\title{
Maintaining the Pharmacy Model: The Catalan Electronic Prescription Infrastructure
}

\author{
Joan Rodon Modol
}

\subsection{Introduction}

This chapter presents the genesis and evolution of the public e-prescription information infrastructure (EPI) of Catalonia, Spain from 2000 to 2013. The implementation of the EPI required a transition from a mainly paper-based and asynchronous prescription model to a digital and synchronous one. This transition involved doing changes into the practices, systems and roles of the CatSalut (the Catalan Health Service), doctors and health providers, pharmacists and Colleges of Pharmacists, and ultimately patients. Our narrative extols those changes and how the pre-existing technological and institutional resources of professionals shaped the design, and evolution of the infrastructure. Our narrative traces those events from the perspective of pharmacists and shows how the installed base of pharmacists was used and extended in a way that maintained and strengthened the pharmacy model.

The reminder of the chapter is structured as follows. In the next section, we present the Catalan model of community pharmacies (see the Chap. 11 for a description of the overall Catalan health system). This section is followed by our narrative of the case. Next we analyze and discuss the implications of our results.

\subsection{Site: The Catalan Model of Community Pharmacies}

The model of pharmacies in Spain compromises multiple components operating at different levels. At the lower level, there is the pharmacist, a health agent who exercises its professional practice in community pharmacies or hospital

J.R. Modol

ESADE Ramon Llull University, Av. Torreblanca 59, 08172 Sant Cugat del Vallès, Spain

e-mail: joan.rodon@esade.edu 
pharmacies by dispensing drugs, producing patient-specific preparations, and other pharmaceutical care tasks (e.g. health promotion, tracking patients' medication record, checking drug interactions, etc.). In order to practice pharmacists must be registered in the College of Pharmacy of the province where they practice.

Community pharmacies are private health facilities of public interest. Pharmacies are the only health establishments authorized to dispense prescription-only medicines and over-the-counter medicines to the general public. Medicines in Spain are publicly funded. Until 2012 medicines were provided to pensioners for free; working age people paid $40 \%$ and those suffering from chronic illnesses paid $10 \%$ of the cost of medicines. From 2012 several copayment reforms at the regional and national level were approved that ended with this scenario (Puig-Junoy et al. 2014). First, a national coinsurance rate of $10 \%$ for retirees with a monthly income-related cap. Second, Catalonia charged temporally a linear one-euro copayment per prescription with a monthly cap. Third, a national reform stopped funding a long list of medicines indicated for minor symptoms.

The ownership of community pharmacies is limited to pharmacists (trained professionals); pharmacy chains are not allowed forms of ownership. One pharmacist or a group of pharmacists can own only one pharmacy. The establishment of pharmacies is regulated responding to demographic and geographic criteria in order to guarantee a homogeneous access of the services to citizens (99\% of Spaniards have a community pharmacy in their municipality). On average a community pharmacy serves approximately 2,000 citizens. Regulations are defined at the national and the autonomous region levels. While the central government is in charge of the general coordination of pharmaceutical care and of matter related to pharmaceuticals such as registration, each autonomous region organizes the planning of the pharmacy system.

In the autonomous region of Catalonia, the main actors that constitute the field are: CatSalut (the Catalan Health Service), the Catalan Council of Pharmacists (CCP), the four Colleges of Pharmacists (which coalesce into the CCP), the community pharmacies, pharmacists, and business organization of pharmacies. ${ }^{1}$ CatSalut is the public insurer that is responsible for planning, purchasing, and assessing health services according to the needs of the population. The CCP is a corporate and public legal entity that represents the interests of all pharmacists in Catalonia, as well as the interests of community pharmacy owners and ensures that regulations are respected.

A core component of the model of pharmacies is the agreement initially signed by the CatSalut and the CCP on January 31st 1995 that regulates the conditions by which pharmacists provide pharmaceutical care, invoice according to the contract economic regulations, temporary fund the dispensed drugs and health products,

\footnotetext{
${ }^{1}$ The FEFAC (www.fefac.cat) is the business organization of Catalan pharmacies. The FEFAC is non-profit federation that aims to defend the interests of pharmacy owners who voluntary enroll it. In 2015 there were about 1,600 (of the 3,000) pharmacies enrolled.
} 


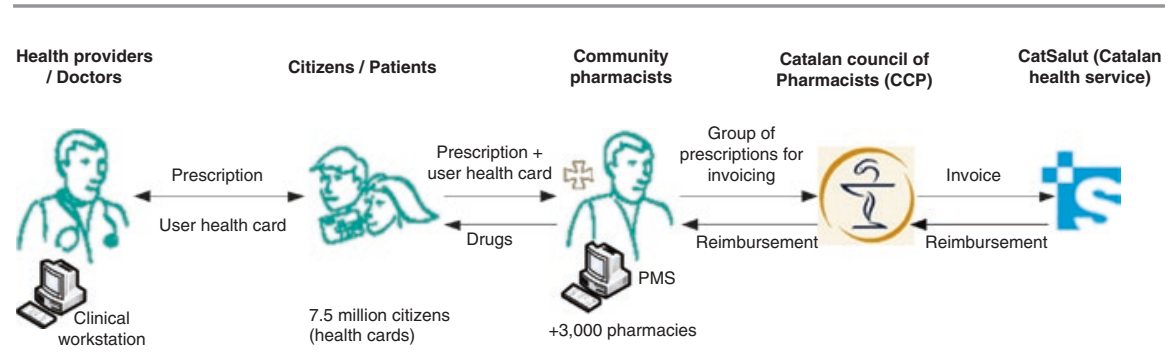

Fig. 5.1 Flows involved in the paper-based prescribing, dispensing and invoicing

continuously deliver health care information to the CatSalut, do health promotion and disease prevention, and perform pharmaceutical surveillance and security alert management of drugs and health products to the population served by the CatSalut. The agreement is continually renegotiated according to changes in the legislation, the profession, and society.

\subsubsection{The Installed Base of Pharmacies}

A core practice of pharmacists is the dispensing of drugs which interacts with other practices (e.g., prescribing, invoicing) and actors (e.g., doctors, patients, $\mathrm{CCP}$, CatSalut), and involves flows of information, patients, money, and so on. Before the implementation of EPI, the flows were as follows (see Fig. 5.1). Once the doctor had decided the drug treatment for a patient the latter was given a paper prescription. Doctors used clinical workstations to generate the prescriptions and print them. The patient took the prescription and her health card $^{2}$ to the community pharmacy, where the drug was dispensed. Then pharmacists stored and signed those paper based prescriptions. Pharmacists used a pharmacy management system (PMS) for tasks such as the management of sales, inventory, or purchasing orders. In 2004, when the EPI project was to start, there were about 35 different types of PMS. Those PMS were developed by pharmaceutical wholesalers, software vendors or individual developers. Periodically, pharmacies grouped the paper-based prescriptions they had dispensed in a given period of time and sent them to the CCP. The CCP then checked all those prescriptions, scanned them, forwarded the scanned and paper prescriptions to the CatSalut, and handled the invoicing for pharmacies. In particular, the CCP submitted a single invoice to the CatSalut. So, the CCP, not pharmacists, was the one in charge of invoicing the CatSalut. The CatSalut reimbursed that invoice to the CCP who checked for errors and finally paid pharmacies according to the signed prescriptions they had previously sent.

\footnotetext{
${ }^{2}$ The individual health card has a magnetic stripe containing data fields such as the code of the insured (the citizen), the name and surname, her number of social security affiliation, type of insured (level of coverage), and the expiration data.
} 


\section{Method}

Data was collected from three main sources: semi-structured face-to-face indepth interviews (20 interviews), participant observation (workshop attendance; informal conversations; direct on-site observation), and archival data (more than 500 press documents, reports, meeting minutes, and videos), aiming at data triangulation (Yin 2003). Data collection has taken place in three intensive period May - August 2008, January - May 2010, and February May 2013. We identified interviewees by referral from other subjects. All the interviews were recorded and immediately transcribed and analyzed next two the archival data and other observations. In that sense, data collection and analysis took place iteratively.

With all the data gathered, we constructed an initial timeline of events for the genesis and evolution of the EPI. We then wrote a rich chronological case story that put at the forefront the role of the installed base. We organized the case narrative into four stages covering the period 2000-2013.

\subsection{Case Narrative}

\subsubsection{Phase 1: Genesis of the e-Prescription Infrastructure in Catalonia (2000-Mid-2004)}

In 2000, the Spanish Ministry of Science and Technology in collaboration with governments of the autonomous regions and the representatives of the diverse professionals involved in prescribing and dispensing - that is, the Colleges of Doctors and the Councils of Pharmacists - started working on the foundations for a common Spanish reference model for e-prescription.

Meanwhile, in 2001 the Catalan Council of Pharmacists (CCP) and the College of Doctors led a successful first pilot of e-prescription in Barcelona for private health involving a hundred private doctors and 25 pharmacies. The CCP proposed the CatSalut to bring that pilot to the public health, but the CatSalut refused it arguing that they were involved in the Spanish project and should wait until it ended. Moreover, as an outcome of this pilot of e-prescription, the CCP and the College of Doctors created Firma Profesional, ${ }^{3}$ a Certification Authority that issued digital certificates for those pharmacists and doctors involved in the pilot (Cordobés 2002b). Meanwhile, from October 1st 2001, the citizens insured by the CatSalut had to bring their individual health card at pharmacies in order to pick up the drugs prescribed at the public health system (Gilabert-Perramon and Prat 2001). During the dispensing process pharmacies had to check whether the individual health card matched the patient data that appeared in the paper-based prescription, and store the data of the patient, the code of the prescription and the dispensed drug. From 2003 those data had to be electronically submitted to the CatSalut (Gilabert-Perramon et al. 2010).

${ }^{3}$ www.firmaprofesional.com 
In short, these events became catalysts for the computerization of all the Catalan pharmacies.

The first draft of the model for the Spanish e-prescription was released in 2002. The model comprised a single central database that would be used by both pharmacists and doctors for prescribing and dispensing respectively. That model dissatisfied the Council of Pharmacists who perceived and argued that the main goal of the central government was to control their practice and to reduce public expenditure on drugs, rather than the use of IT for pharmaceutical care (Cordobés 2002a). Finally, in 2004 in accordance with the decentralized health system of Spain and with the Spanish law for the cohesion and quality of the national health system (CohesionAct 2003) diverse autonomous regions started their own e-prescription projects.

It was in mid-2004 when the CatSalut set the foundations for the building of e-prescription infrastructure (EPI) in Catalonia involving all health agents (e.g., health providers, college of doctors, Catalan Council of Pharmacists). With EPI, the CatSalut sought to improve the efficiency of the health system by streamlining patients' access, containing drug expenditures, and reducing prescription and dispensation errors due to lack of coordination between the agents involved in those processes (Gilabert and Cubi 2009; Gilabert-Perramon et al. 2010). To achieve those goals, the CatSalut proposed doing changes to existing practices. For instance, doctors would not make individual prescriptions anymore but medication plans ${ }^{4}$ (see Fig. 5.2) that would last up to 1 year; that in turn, would eliminate the need for co-presence of patients and doctors in the prescribing process and would reduce the number of patient appointments with primary care. Patients would pick up medicines at any pharmacy according to a concrete temporal window thus avoiding that patients accumulated more drugs than necessary. Patients would have to bring their medication plans and their health cards to pick the medicines at pharmacies. Medicines would be dispensed at any pharmacy regardless of the location of the prescriber.

The CatSalut defined two core requirements for EPI. First, all the data - i.e., prescriptions, dispensations, invoices, patients, drugs, health providers, doctors, pharmacies, pharmacists - should be integrated and accessible online by the diverse stakeholders - CatSalut, doctors, and pharmacists. Second, the processes of prescribing and dispensing should run in real time. Accordingly, the CHS would have information about the acts of prescribing and dispensing in real-time and would be able to influence both acts for instance by forcing the prescription of generics.

To fulfil these requirements and in line with the reference model defined by the Spanish Ministry of Science and Technology in 2002, the CatSalut proposed a model (see Fig. 5.3) consisting of a central system owned and managed by the CatSalut (called SIRE) that contained an integrated database with all the data. On

\footnotetext{
${ }^{4} \mathrm{~A}$ medication plan has a bar code that is read in the pharmacy (top right in Fig. 5.2) and includes (columns from left to right in Fig. 5.2): the drug, the dose and frequency, duration of treatment, doctor and health centre, temporal window with the validity of the plan, and comments and observations.
} 


\section{Pla de medicació}

\section{Nom i cognoms del/de la pacient} TASA1030101002
Informació per a la farmàcia

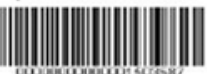

Tractaments de llarga durada

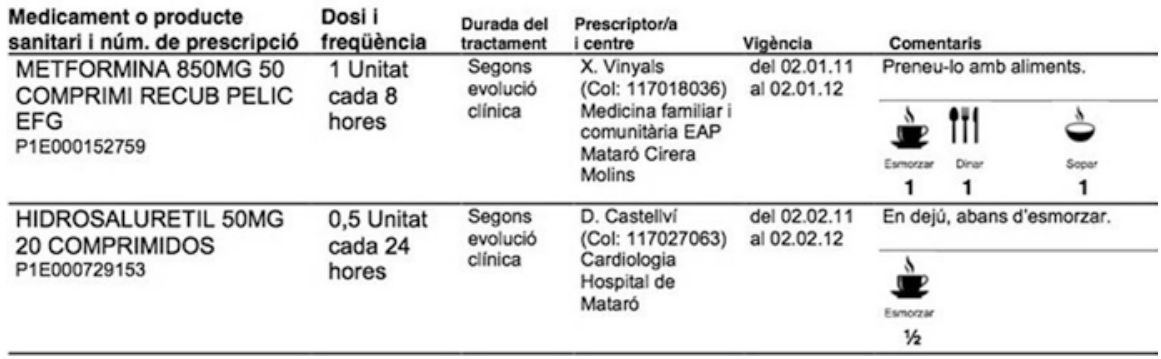

Fig. 5.2 Example of the medication plan (printed on paper) that doctors give patients

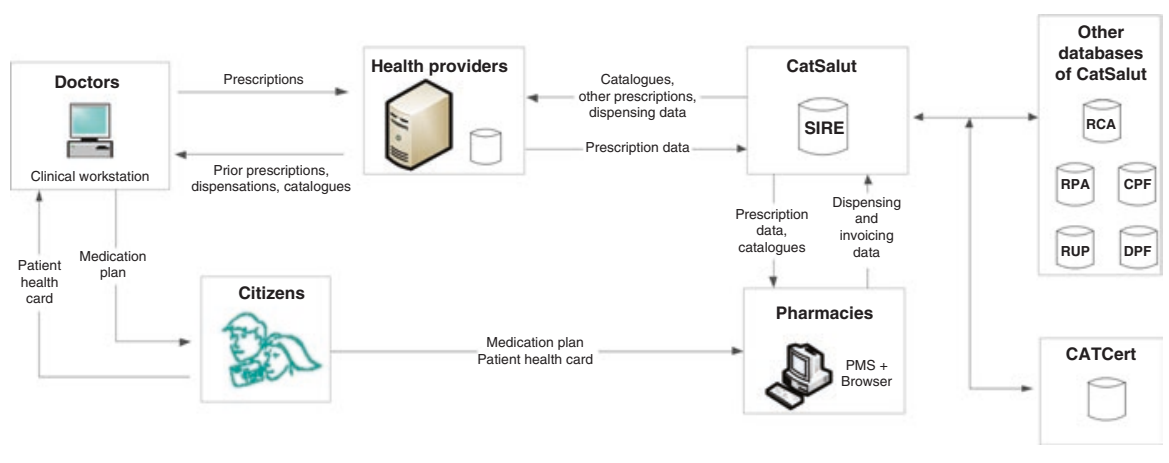

Fig. 5.3 Initial EPI model proposed by the CatSalut

the one side, the health providers would have to interconnect their systems with the CatSalut system (SIRE). On the other side, pharmacists would connect directly to SIRE - through a browser - for the dispensing and invoicing processes.

\subsubsection{Phase 2: Mobilizing the Pharmacists' Installed Base (Mid-2004-Mid-2006)}

Although CatSalut's model was framed as an efficient and effective way to conform to the two core requirements, the CCP argued that it was bypassed in the dispensing and invoicing and that was a threat to the existing pharmacy model. Such a direct 


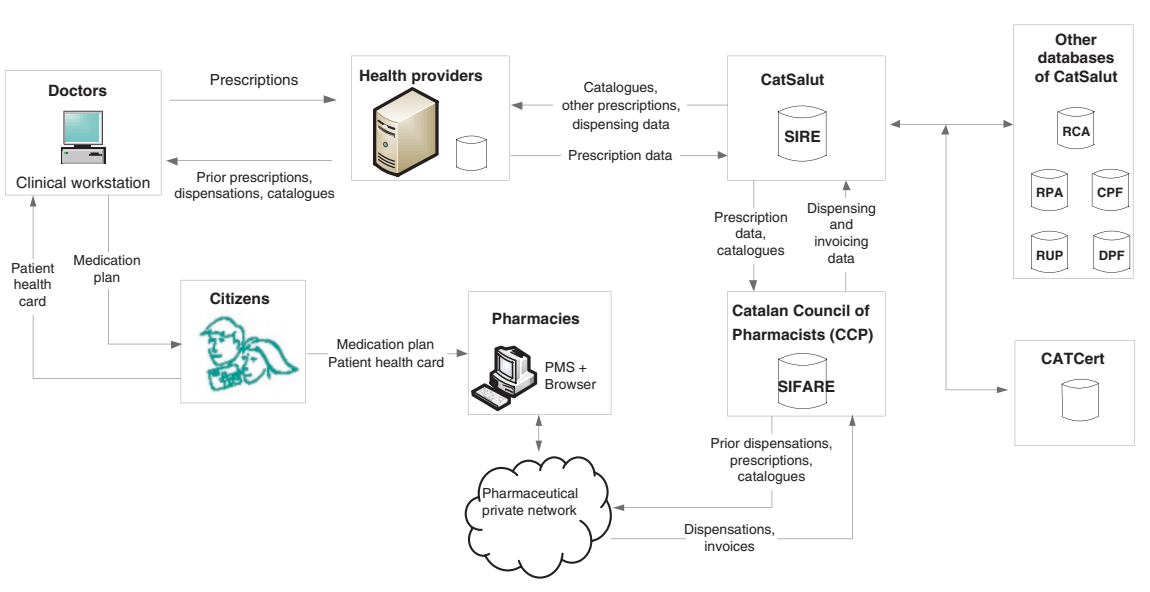

Fig. 5.4 Alternative EPI model proposed by the CCP

relationship between the CatSalut and pharmacists was against the terms of the existing pharmaceutical agreement. It weakened the position of pharmacists in front of the CatSalut who could more easily change the conditions that regulate pharmacies on an individual basis.

As a response, the CCP then proposed an alternative model on the pharmacists' side (see Fig. 5.4) consisting of a private network (VPN) that would interconnect all the pharmacies plus a central server (called SIFARE) that replicated the data of the CatSalut system that was needed for pharmacists - i.e., prescriptions, dispensations and data catalogues. Both the private network and SIFARE would be owned by the CCP. Community pharmacies would not have a direct access to SIRE (the CatSalut system) but instead to SIFARE (the CCP system) through the VPN, and the SIFARE would synchronize in real time with the SIRE for dispensing and invoicing. A vicepresident of the CCP related the pharmacy model with the VPN in the following terms: "We are a network [the pharmacy model in Catalonia] that needs a network [the VPN]... Politicians argue for a capillary pharmacy model; that is, that pharmacies are spread throughout the country. We must transfer this network of pharmacies to the electronic world. It cannot happen that what is there physically does not exist electronically." Moreover, this new conceptual model guaranteed that all pharmacies would have the same conditions for dispensing and invoicing, and offered the opportunity for the professional development of pharmacists as they could implement new digital services on SIFARE and the VPN.

Initially, the CatSalut did not see the CCP's model (Fig. 5.4) favorably. The CCP was afraid that it could penalize the fulfilment of the two central requirements of data integration and real-time processes. Yet, the CatSalut saw that the CCP was a legitimized actor whose involvement in the project was critical for its success. Without the CCP, it would be very difficult to mobilize pharmacists. So, after some negotiations the CatSalut bowed to the interests of the CCP and the pharmacists, and accepted the CCP's model on May 2005. A manager of the CatSalut and leader 
of the EPI project retrospectively justified the final model in the following terms: "Why do pharmacies invoice us through the CCP? Well, I think it is something that is good for both of us. It is not the same to have 3,000 interlocutors as to have just one as with the CCP. Of course it has its good and bad aspects for both sides. However, for the CCP this means empowering the collective and serving in a role as representative of a collective. I imagine that the members of the CCP [pharmacists] are interested in somebody that brings them together and defends them in the negotiations. Moreover, this relationship structure is not new, it has some history."

The governance structure of the project also helped consolidate the CCP's model. It consisted of two main committees: a steering committee, and an executive committee later called follow-up committee, in which diverse members of the CatSalut, CCP, health providers and other stakeholders were present. ${ }^{5}$ A manager of the CatSalut and leader of the EPI project depicted that committee structure as follows "This has been an integrative project from the first day... We started doing things all together [the sector]. Accordingly, we built this governance structure consisting of multiple committees that included all the agents."

In building the architecture for the model, the CatSalut opted for an architecture for SIRE based on web services. That is, the systems of health providers and those of the CCP would interact with SIRE through web services using SOAP and XML. The CatSalut developed two sets of web services (see Fig. 5.5): one set for prescribing that would be used by health providers, and another one for dispensing and invoicing that would be used by the CCP.

A main design decision of the CCP was that SIFARE should be as transparent as possible for pharmacists such that they would not be forced to use an additional information system for dispensing and invoicing. This meant that pharmacists should be able to integrate their existing pharmacy management systems (PMS) with SIFARE in a way that minimized the changes to their practices. To achieve so, the CCP boosted in 2005 a recognition program for PMS vendors that it had launched in 2004 aiming to guarantee that PMS vendors fulfilled the needs and requirements of community pharmacists set by the CCP and CHS. The initial scope of the recognition program had been that of patient's health card reading and data transmission for invoicing. In 2005 the CCP extended the recognition program to include e-prescription. The CCP developed a set of web services for SIFARE and an application program interface (API) exposed in a DLL for the convenience of PMS vendors. Those vendors who passed the recognition program got the API from the CCP to interconnect their PMS solutions with SIFARE. That is, getting that recognition became a necessary condition for PMS vendors to remain in the market. From the about 35 PMS solutions that existed in 2004, only 9 got the recognition. Of the nine recognized PMS, five PMS got the recognition in 2005, one in 2007 and three in 2008. Five of those nine recognized PMS were developed, commercialized and

\footnotetext{
${ }^{5}$ In 2014 this organizing structure was still running. The steering committee meets every quarter, and the follow-up committee meets monthly. Likewise, working groups are created when new domains of study are required (e.g. prescribing and dispensing by active ingredient, prescribing and dispensing of narcotics, professional filters, certification and authentication of professionals).
} 


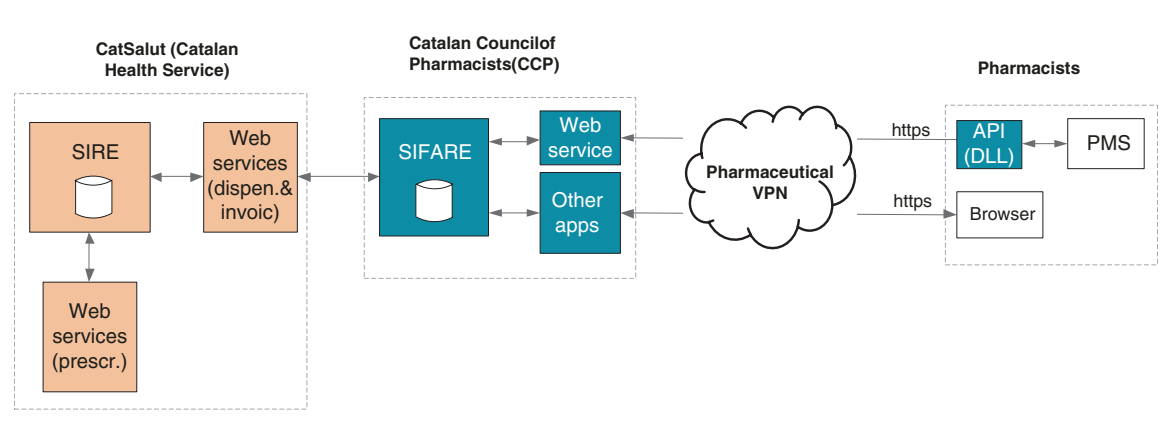

Fig. 5.5 EPI architectural components on the pharmacists' side.

supported by pharmaceutical wholesalers, and the other four by software vendors. The rest of PMS solutions were progressively discontinued.

Overall, the EPI architecture (Fig. 5.5) was modular in production. It decomposed the EPI into loosely coupled components: SIRE, SIFARE, and PMS that were interconnected through web services, and it influenced the role of actors in the project. For instance, the CPP would be in charge of (1) building the virtual private network (VPN) for pharmacies, (2) developing the SIFARE and (3) assuring that pharmacists integrated their PMS with SIFARE.

The security model, a central component of the EPI architecture, was defined by the Catalan Certification Agency ${ }^{6}$ and included the following kind of requirements (eSignAct 2003): electronic certificate for professionals for their authentication (SAML authentication), digital signature of all the professional tasks, verification of signature, data encryption to ensure integrity and confidentiality, and obligatory use of patient health card and security code to access patient data. For the communication between SIRE and SIFARE they established a secure channel (SSL-Two-Way) ensuring the origin and destination of information and confirming that they are who they say they are. The CCP would act as a Registration Authority ensuring that any digital certificate is bound to the pharmacist to whom it is assigned in a way that assures non-repudiation.

Regarding the communications, pharmacies would be connected through a virtual private network (VPN). After a tender for the VPN in 2006, the CCP signed an agreement with a telecom provider. That agreement homogenized the service and price conditions for all the pharmacies, regardless of their location or size. Each pharmacy would have an asymmetric digital subscriber line (ADSL) and a backup integrated services digital network (ISDN) line to connect to the central server of the CCP - SIFARE. CCP would coordinate the rollout of the VPN with that of the EPI. From 2012 some pharmacies started setting up 3G back-up connections.

\footnotetext{
${ }^{6}$ The Catalan Certification Agency is a governmental agency that was set up in 2002 in order to implement and rollout the digital signature in all the Catalan governmental institutions and provide services to those organizations ensuring that the electronic transactions fulfill the legal guarantees.
} 


\subsubsection{Phase 3: Pilot and Rollout of EPI (Mid-2006-2010)}

In 2005, the CatSalut had worked on a detailed list of functional requirements, and made a public tender for the development and implementation of SIRE. The goal was to launch a pilot by early 2006. With the first version of the SIRE web services for dispensing and invoicing, the CCP developed a first version of the SIFARE web services and the first API for PMS vendors. With that API, PMS vendors had to adapt their solutions for e-prescription, and install and configure the new version of the PMS in pharmacies.

In 2006 the CatSalut and the CCP signed an appendix to the pharmaceutical agreement which established the clauses for the development of the pilot for the EPI, and made explicit the role of the CCP. This appendix helped stabilize the EPI by clarifying the roles of actors. On April 2006 a first pilot was inaugurated. However, due to repeated technical problems and errors, the CatSalut stopped the pilot and started a new version of SIRE that addressed those problems. On May 2007 the Catalan Parliament passed an act that regulated e-prescription (ePresDecree 2007; ePresOrder 2008). By the end of 2007, the CatSalut resumed the pilot involving five basic heath areas in two of the seven health regions of Catalonia (Girona and Terres de l'Ebre). The general practitioners, pharmacies and patients of those heath regions were gradually added into the pilot; the general practitioners decided which patients should be prescribed electronically. On May 2008 the pilot was satisfactorily completed. The pilot had involved 63 doctors, 39 pharmacies and 15,000 patients, and more than 300,000 prescriptions had been dispensed (GilabertPerramon et al. 2010). Then the rollout of the EPI in primary care started. It was organized into five phases, each involving one or more health regions (see Table 5.1).

The fifth phase of the rollout involved the health region of Barcelona where there were about 2,200 of the more than 3,000 pharmacies in Catalonia. This last phase was also a very critical one as it could destabilize the whole project. First, since it took place in Barcelona, news about any failure would spread fast and that would have a greater political impact for sponsors. Second, it involved a considerable increase in the number of transactions, health providers, pharmacies, and patients. Accordingly, it required upgrading the technological infrastructure. On the side of pharmacists, the CCP re-scaled the hardware of SIFARE four times from 2006 to 2012 in order to accommodate the growth in the number of transactions derived from the scaling of EPI (see Table 5.3).

Table 5.1 Roll out of the EPI at primary care

\begin{tabular}{l|l|l}
\hline Phase & Health regions involved & To start on \\
\hline 1 & Girona, Terres de l'Ebre & May 2008 \\
\hline 2 & Camp de Tarragona & October 2008 \\
\hline 3 & Lleida, Alt Pirineu - Aran & October 2008 \\
\hline 4 & Catalunya Central & April 2009 \\
\hline 5 & Barcelona & May 2009
\end{tabular}


An important concern for the $\mathrm{CCP}$ was the cost of the technical infrastructure for the CCP and pharmacists. To overcome that concern, the CCP actively sought funding for SIFARE and VPN as well as the investments that pharmacists had to carry out (e.g. the connectivity services to the VPN, upgrading of PMS, the digital signatures, swipe card and swipe card readers). On the one hand, the main idea for funding the technological infrastructure of the $\mathrm{CCP}$ was that the reduction of cost related to the processing paper-based dispensations for invoicing (e.g. scanning and checking of dispensations) would be dedicated to pay the new technological infrastructure. Likewise, in 2008 the CCP got a subsidy from the Center of Innovation and Development of the Catalan Government. On the other hand, regarding the funding of pharmacists' investments, by early 2008 the CCP signed an agreement with a Spanish bank. According to that agreement, the bank would partially assume the connectivity costs of pharmacists and provide them with digital certificates and swipe card readers for free. ${ }^{7}$ Later in 2010 the CCP received some financial aid from the Department of Health of Catalonia for the connectivity of pharmacies. Moreover, a condition for those PMS vendors passing the recognition program was that they would assume the costs of adapting their systems to interconnect with SIFARE and the costs of upgrading the PMS for their customers (the pharmacies).

Additionally, in order to support pharmacists during the rollout, the $\mathrm{CCP}$ created in 2008: (1) an e-newsletter to inform them; and (2) an IT Operations Center to support pharmacies in resolving technical problems, performing a baseline audit to check whether pharmacies were ready for e-prescription, informing them about the calendar for the rollout in their area, and support pharmacies in their daily practices with EPI. Later the CCP extended the scope of service of the IT Operations Center to include the monitoring of the infrastructure in order to detect failures before pharmacists realized them. The aim was to anticipate problems, keep pharmacists informed, as well as force and help the telecom provider to resolve incidents.

The rollout was completed during the third quarter of 2010. At that time all the more than 3,000 Catalan pharmacies were using the EPI. On August 2010 the prescriptions dispensed electronically accounted for $50 \%$ of all the prescriptions being billed $^{8}$ (see Table 5.2 for an evolution of electronic prescriptions being dispensed). In 2011 the CatSalut estimated that the e-prescription had saved around 5,100,000 patient appointments with primary care centers for collecting recipes. During 2011 the EPI was rollout at the specialized care and was completed by mid-2014. The rollout was extended to the geriatric residences and home care in 2012, and to mental care in 2013.

\footnotetext{
${ }^{7}$ Those conditions applied to pharmacies having a certain volume of business with the bank. In 2012 the funding agreement with the bank was still in place and the number of pharmacies benefiting from it had remained constant (around 1,300).

${ }^{8}$ In 2010 electronic prescription was only running at primary care, not at hospital and specialized care. The CatSalut encouraged the use of EPI among health providers by means of incentives defined in the multi-annual contracts that CatSalut signs with health providers.
} 
Table 5.2 Electronic prescriptions being dispensed

\begin{tabular}{l|l|l}
\hline \multirow{2}{*}{ Year } & $\%$ & \\
\cline { 2 - 3 } & $\left(\right.$ Electronic prescriptions/prescriptions billed $\left.{ }^{\mathrm{a}}\right)$ & Daily volume \\
\hline 2011 & 73,6 & 385.000 \\
\hline 2012 & 85,3 & 430.000 \\
\hline 2013 & 91,2 & 460.000 \\
\hline 2014 & 95,4 & 522.100 \\
\hline
\end{tabular}

Source: CatSalut

aPrescriptions billed includes the sum of electronic and paper-based prescriptions of all the primary care levels

\subsubsection{Phase 4: Adaptation and Innovation on the Side of Pharmacists (2011-2013)}

The functional evolution of the EPI has come from on the one hand, adaptations that are triggered by the CatSalut and the Catalan Spanish Governments, and on the other hand, new services that the CCP launches independently of the CatSalut.

In the first case, from 2006 to 2013 the CatSalut released 29 versions of SIRE web services with new functionalities (e.g. the inclusion of prescribing filters, the prescription by active ingredient, messaging among professionals, overdosing, and consult generic alerts). These functionalities reflect the approval of new laws, new requirements from the CatSalut and health professionals, and the new EPI rollouts at specialized and mental care, and geriatric residences. When the CatSalut creates a new SIRE web service for the dispensing and invoicing processes, the CCP immediately creates a new SIFARE web service and updates the API for PMS vendors. For instance, in 2012 the Catalan Government approved the "euro per prescription" tax that forced patients to pay an extra-euro for each drug dispensed at pharmacies (EuroPerPresAct 2012). To support this new tax the CatSalut developed three new web services. Then the CCP created three new services and the API 3 so that PMS vendors could adapt their applications to support such a tax. On average it takes between 6 and 8 months from the moment the API is delivered to PMS vendors until they update their PMS and install them in all the pharmacies. Similarly, in 2011 and 2012 the Spanish government passed two co-payment acts (copaymentReform 2011, 2012) which entailed that pensioners would have to partially pay medicines based on their income and with a monthly cap. The calculation of the final amount and the payment took place in the pharmacy when the patient picked the drug. This act entailed making changes to SIRE and SIFARE web services and to PMS.

However, it did not always happen that the release of a new version of an existing SIRE web service was followed by a new release of the corresponding SIFARE web service, and in turn, a change in the API for PMS vendors. That happened for instance, when a new feature included in a new SIRE web service was not mandatory (not required by law). Then the $\mathrm{CCP}$ might consider that the new feature did not add enough value to pharmacies, or that pharmacies were not ready, or that the CCP itself or the PMS vendors were not ready to implement that new version. Accordingly, 
Fig.5.6 Interdependencies between SIRE and SIFARE web services and API

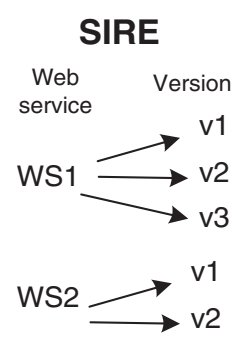

\section{SIFARE}

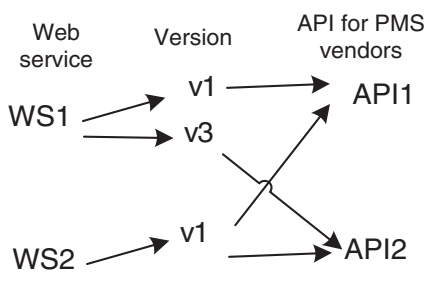

the modular architecture of the EPI (Fig. 5.5) created a sequential interdependency between the CatSalut, the CCP, the PMS vendors and pharmacies in the development and release of new services (Fig. 5.6 illustrates this idea). This enabled the $\mathrm{CCP}$ to set the pace of evolution of the EPI by accommodating the changes triggered by the CatSalut to the needs and capacities of PMS vendors and pharmacists and its development resources.

The CCP has developed five versions of the API (which includes more than 30 web services): a first version in 2006 coinciding with the EPI pilot; a second one in 2009 before the massive roll-out in Barcelona; a third version in 2012 coinciding with two regulatory changes - the "euro per prescription" (EuroPerPresAct 2012) and co-payment act (copaymentReform 2011, 2012)-; a fourth version in 2012 to support the inclusion of paper-based prescriptions (e.g. generated at specialized care or other public mutual insurance companies) into EPI in order to dispense them electronically; and a fifth version in 2013 to support new professional services for pharmacists that are part of the SIFADATA initiative (which aimed to leverage on technology to digitalize pharmacists' processes and do analytics of the data at SIFARE).

On the other hand, the evolution of the EPI also came from new functionalities and services that the CCP developed on its own initiative -i.e., independently of the CatSalut. The rationale for those services was consistent with the vision of the CCP about the model of EPI. In particular, the CCP saw the EPI as an opportunity to re-professionalize the practice of pharmacists. For instance, from 2008 the CCP has been developing web apps to support pharmacists' work (e.g. tools to support the invoicing, management of alerts, management of users, and management of digital signature). Another example of a professional services tied to SIFARE was the SIFADATA initiative that the CCP launched by on 2012. This initiative involved redesigning other (than dispensing and invoicing) processes that pharmacists carry out daily and leveraging on the SIFARE and the VPN to digitalize them; this included for instance, the management of recipe and narcotics books, or the pricing of magistral formulae. In the case of the management of recipe and narcotics books, although most of the PMS stored those documents, pharmacists still had to periodically print those documents and carry them to the Department of Health. As part of the SIFADATA initiative the process was redesigned in a way that data would not only be locally stored at the PMS but also at SIFARE. Then pharmacists would electronically sign and submit the data stored 
at SIFARE to the Department of Health without any need to print them. With the development of this new kind of services, the CCP helped pharmacists by channeling their work practices through the PMS. At the same time the CCP boosted the use of the SIFARE and the VPN, and strengthened its role as service provider of pharmacists.

An assumption underlying this initiative was that the entry door for pharmacists to all those services must be the PMS. This requires the cooperation and involvement of PMS vendors who are expected to adapt their solution to the new services. In order to achieve so, the CCP leveraged the governance structure with PMS vendors. From the early stages of the project, the CCP created an advisory committee for technology and communications which brings together every quarter the CCP and the recognized PMS vendors to discuss about the status of the EPI and agree on its evolution - e.g. agree on the new requirements and services, on the pace of implementation of those services. What happened until 2012 was that, most of the adaptations that required developing new web services were triggered by the CatSalut, so eventually the PMS vendors had not choice implement them. However, with the development of professional services that are independent from the CatSalut, the PMS vendors cannot be obliged to implement them. Hence, PMS vendors became central actors in the strategy of the CCP regarding the new professional services. The CCP saw that for the launch of those professional services, the consensus with and involvement of the PMS vendors was much more critical. So the $\mathrm{CCP}$ felt the need to adapt the governing strategy with PMS vendors. To do so, in 2013 the CCP reoriented the focus of the recognition program more towards technical aspects and professional services.

Regarding those services that exploit the VPN, in 2011 the CCP set up a company called TicFarma seeking to transform all the pharmacies into a corporation which offered telecommunication services to the same pharmacies and pharmacists. With TicFarma, the CCP leveraged its ownership of the VPN to increase its bargaining power in front of telecom providers. TicFarma was a tool to: (1) reduce the connectivity costs for pharmacists, and (2) launch new telecommunication services for pharmacists. Moreover, the CCP used TicFarma's profits to pay the cost of the technological infrastructure consisting of the SIFARE and the VPN. Through TicFarma the CCP reinforced its role as a service provider for pharmacists.

\subsection{Analysis and Discussion}

Prior section has depicted the evolution of the Catalan e-prescription infrastructure (EPI) from the perspective of pharmacists. In particular, this chapter has narrated the transition from a paper-based asynchronous prescription model to a digital synchronous one. Our narrative has focused on how the Catalan Council of Pharmacists' (CCP) shaped that transition by appreciating the installed base and the potentialities of the EPI. Table 5.3 summarizes the evolution of the EPI according to several dimensions (timeline of events, regulations, and governance and architectural components). 


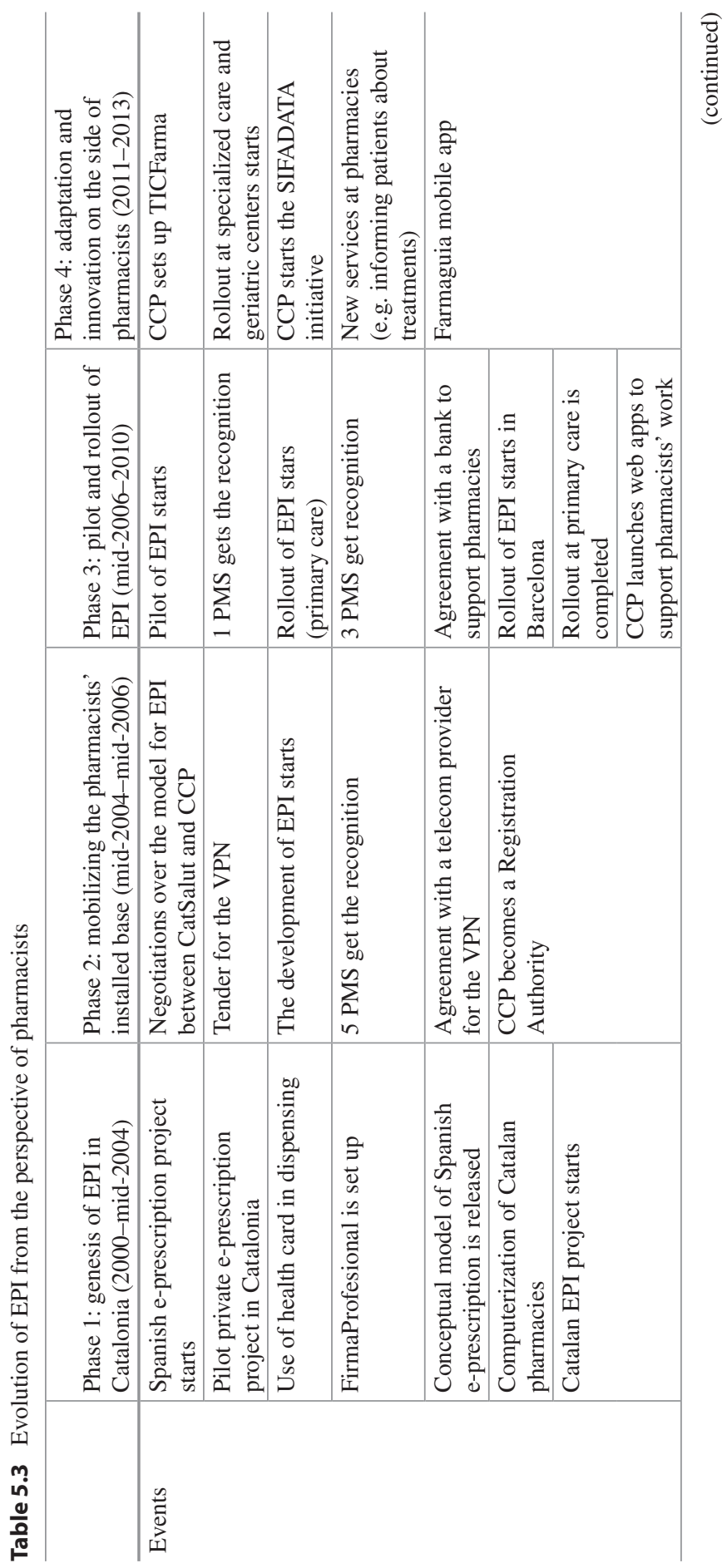




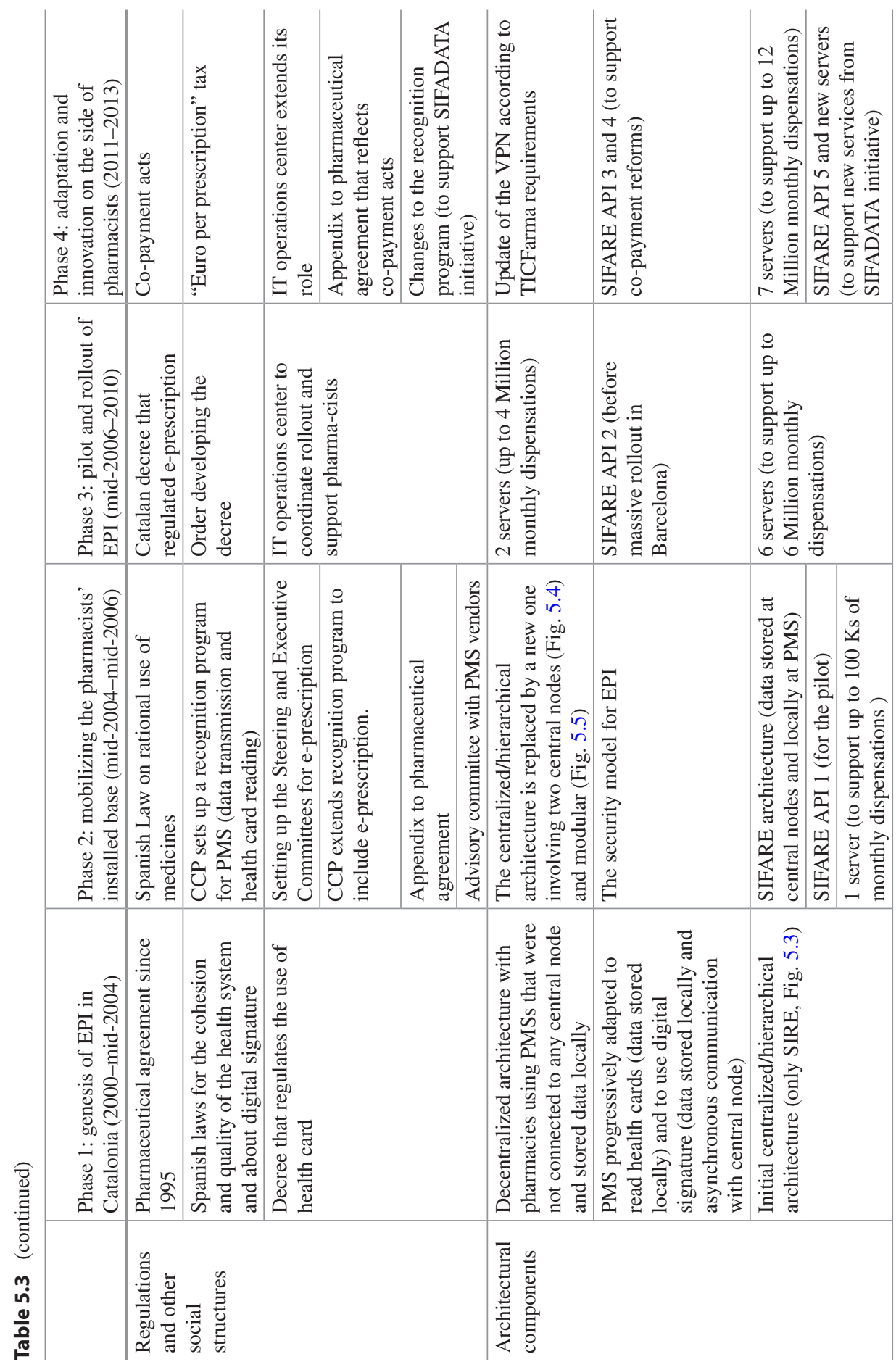


On the one hand, our study shows how in building EPI, the exploitation and expansion of the installed base of pharmacists helped maintain the existing pharmacy model. Some of the technical components of EPI (e.g., SIFARE, the VPN, the security model) were built on and reinforced the installed base involving the pharmaceutical agreement and the pharmacy management systems (PMS). This also demonstrates that in building the EPI, the CCP thought in terms of what might happen - e.g. what might happen if the initial model for EPI proposed by the CatSalut (Fig. 5.3) was finally built. The CCP's concern was that the initial architecture proposed by the CatSalut could fragment the existing collective pharmaceutical agreement into individual agreements between CatSalut and pharmacists. So the CCP's counter-proposal for the EPI architecture protected the existing pharmaceutical agreement by avoiding any direct relationship between CatSalut and pharmacists.

Yet our narrative shows that the decision of the CCP to go for a new architectural model (Fig. 5.4) cannot be viewed simply as a radical shift at one point in time involving only individuals deliberate planning -i.e., choices and goals, matching means and ends-, but as a series of cumulative capabilities and events occurring from year 2000 that conferred legitimacy to the $\mathrm{CCP}$-e.g., the pilot of e-prescription in the private health in 2001, the computerization of all pharmacies in 2003, the early version of the recognition program in 2004 to support the reading of individual health cards at pharmacies, and the implementation of health card recognition technologies.

On the other hand, this chapter also shows how the CCP also thought of EPI in terms of potentialities. For instance, on the side of pharmacists, the new recognition program and SIFARE API gave continuity to pharmacists' practices (pharmacists could keep using their PMS) while at the same time shifted the relationship between PMS vendors and pharmacists because the pace of updates and innovations of PMS would now be set by the pharmacists themselves (through the CCP). Moreover, the core components of EPI (SIFARE, VPN and recognition program) have enabled the CCP to act as a service provider and to foster innovation on new services for pharmacists (e.g. the SIFADATA initiative, TICFarma) and also for citizens (e.g. health information services offered through a portal www.farmaceuticonline.com, an app called farmaguia for locating pharmacists and informing about opening hours).

Finally, this chapter has presented a trajectory of an electronic prescription infrastructure. We argue that the longitudinal nature of our study (which covers the period 2000-2013), and our focus on the continuous causal interactions among multiple socio-technical components of the infrastructure has enabled us to give prominence to the role of the installed base in the evolution of the e-prescription infrastructure.

Acknowledgements This research was funded by the program "Internacionalització de la Recerca dels grups de recerca de la URL, un programa impulsat per la Universitat Ramon Llull amb la colllaboració de l'Obra Social 'la Caixa'". 


\section{References}

CohesionAct. Ley 16/2003, de 28 de mayo, de cohesión y calidad del Sistema Nacional de Salud, en materia de prestación farmacéutica, BOE n.o 128 of May 29th 2003, Spanish Government, p. 20567-88; 2003.

copaymentReform. Real Decreto-ley 9/2011, de 19 de agosto, de medidas para la mejora de la calidad y cohesión del sistema nacional de salud, de contribución a la consolidación fiscal, y de elevación del importe máximo de los avales del Estado para 2011, BOE n²00 of August 20th 2011, Spanish Government; 2011.

copaymentReform. Real Decreto-ley 16/2012, de 20 de abril, de medidas urgentes para garantizar la sostenibilidad del Sistema Nacional de Salud y mejorar la calidad y seguridad de sus prestaciones, BOE $n^{\circ} 98$ of April 24th 2012, Spanish Government; 2012.

Cordobés A. Receta electrónica (I). Proyecto Pista y repercusiones sobre la oficina de farmacia. Offarm. 2002a;21(8):142-50.

Cordobés A. La receta electrónica (II). Proyectos de las comunidades autonomas. Offarm. 2002b;21(10):148-56.

ePresDecree. DECRET 159/2007, de 24 de juliol, pel qual es regula la recepta electrònica i la tramitació telemàtica de la prestació farmacèutica a càrrec del Servei Català de la Salut, DOGC $\mathrm{n}^{\circ} 4934$ of July 26th 2007, Catalan Government; 2007.

ePresOrder. 'ORDRE SLT/72/2008, de 12 de febrer, per la qual es desplega el Decret 159/2007', DOGC n ${ }^{\circ} 5081$, Catalan Government; 2008.

eSignAct. Ley 59/2003, de 19 de diciembre, de firma electronica, BOE n.o 304 of December 20th 2003, Spanish Government; 2003. p. 45329-43.

EuroPerPresAct. Llei 5/2012, de 20 de març, de mesures fiscals, financeres i administratives i de creació de l'impost sobre les estades en establiments turístics, article 41, Capítol 21, CatSalut; 2012.

Gilabert A, Cubí R. La receta electronica en Cataluña (Rec@t):¿prescribimos o recetamos? Aten Primaria. 2009;41(6):298-9.

Gilabert-Perramon A, Prat A. La utilización de la tarjeta sanitaria individual (TSI) en las oficinas de farmacia. Informática y Salud. 2001;33:1713-4.

Gilabert-Perramon A, Lopez-Calahorra P, Escoda-Geli N, Salvadó-Trias C. Receta electronica en Cataluña (Rec@t): una herramienta de Salud. Med Clin. 2010;134(1):49-55.

Puig-Junoy J, Rodriguez-Feijoó S, Lopez-Valcarcel BG. Paying for formerly free medicines in Spain after 1 year of co-payment: changes in the number of dispensed prescriptions. Appl Health Econ Health Policy. 2014;12(3):279-87.

Yin RK. Case study research: design and methods. Thousand Oaks: Sage; 2003.

Open Access This chapter is distributed under the terms of the Creative Commons AttributionNonCommercial 2.5 International License (http://creativecommons.org/licenses/by-nc/2.5/), which permits any noncommercial use, duplication, adaptation, distribution and reproduction in any medium or format, as long as you give appropriate credit to the original author(s) and the source, provide a link to the Creative Commons license and indicate if changes were made.

The images or other third party material in this chapter are included in the chapter's Creative Commons license, unless indicated otherwise in a credit line to the material. If material is not included in the chapter's Creative Commons license and your intended use is not permitted by statutory regulation or exceeds the permitted use, you will need to obtain permission directly from the copyright holder.

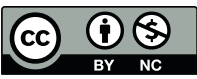

